\title{
Heritability of Annual Earnings in Thoroughbreds*
}

\author{
Yasuyoshi MORITSU, Yuka KIMURA, and Shun ICHIKAWA \\ Laboratory of Animal Breeding, Department of Dairy Science, Hokkaido College of Arts and Science, Ebetsu, \\ Hokkaido 069, Japan
}

(Received 29 July 1991/Accepted 15 October 1991)

\begin{abstract}
The heritabilities of annual earnings in Thoroughbreds of the Japan Racing Association were investigated and estimated using SAS. The records of annual earnings were obtained from the Japanese Racing Annual, in which each horse's record is given by sire. The data of 3-, 4- and 5-yr-old horses from the six years 1982 to 1987 were used, and the data were restricted to include the offspring of sires having at least 30, 50 and 20 progeny for 3-, 4- and 5 -yr-old horses, respectively. The total numbers of sires and progeny in the age classes were 72, 84, 82 and 3675, 7999, 3454, respectively. In the linear model, the year of the race and sex were assumed to be fixed effects, while sire and residual were assumed random effects. Heritabilities were calculated based on the intraclass correlation of paternal half-sibs. Since the distribution of annual earnings did not distribute normally, the three transformations of square root, fourth root and natural logarithm were applied. The heritabilities obtained by square root transformation tended to be the highest estimates. By age group, the heritability estimates were the greatest for 3-yr-old horses, followed by 4 -yr-old horses, and the lowest estimates less than 0.08 were obtained for 5 -yr-old horses. The heritabilities of annual average earnings, as annual earnings per start, were higher than annual earnings for 3-yr-old horses. In this case, the highest estimates of heritability were obtained by square root transformation, when variance components were computed by TYPE 1 and REML in SAS, these estimates were 0.25 and 0.23 , respectively.
\end{abstract}

Key words: annual earnings, heritability, Thoroughbreds

Jpn. J. Equine Sci. 2 : 11-16, 1991

\section{サラブレッド種における年間収得賞金額の遺伝率}

\author{
森津康喜, 木村友香, 市川 舜 \\ 北海道文理科短期大学酪農科家畜育種学研究室 干069 北海道江別市文京台緑町582-1
}

サラブレッド種の競走能力を示す評価值として は, 一般に収得賞金額, 走行タイム, 負担重量と 着差に基づく performance rate などが広く知ら れている。これら評価值の遺伝率については, Langlois と Tolley らが総説のなかでこれまでに 報告された各国研究者の推定值を詳細に紹介して

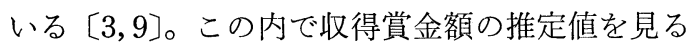
と，その值は報告者によって変動の大きいことが
筧われる。またわが国での報告例は，渡辺らが 3 歳馬を対象に推定した0.49の值が示されているの みである $[10] 。$

一方，種雄馬の能力を後代の記録から評価する 時, 後代の競走能力の評価值をどれにするかは重 要な問題となるが，年間収得賞金額を用いる方法 は，他の評価值を採用するよりも要因の補正や集 計が簡便であることから, 現在も一部でリーディ

\footnotetext{
* In this paper, the age of horses are based on Japan Racing Association Standards whereby a horse is considered a 1-y-0 at birth. Therefore, a 2-y-o in Japan is a yearling in other countries, 3-y-o is a $2-\mathrm{y}-\mathrm{o}$, etc.
} 
ング・サイアー・ランキングやアーニング・イン デックスという名称で種雄馬評価に利用されてい る。こうした現状を考慮して, Ojala はフィンラ ンドのトロッター用種を対象に, 各年度ごとに集 計された競走記録を遺伝的評価も加えて有効に利 用することを目的とし，出走年齢別にそれらの分 布特性と遺伝率の推定を行なっている〔5]。これ に対してわが国のサラブレッド種の競走記録につ いて同様な検討を加えた報告は見あたらない。

そこで本研究は, サラブレッド種の年間収得賞 金額を取り上げ，各出走年齢別に分布特性と遺伝 率を推定し，それらの特徵を把握することを目的 に行なった。

\section{材料と方法}

供試記録は, 中央競馬に抒いて出走し, サラブ レッド血統センター発刊の競馬年鑑に掲載された, 各馬の年度ごとの種雄馬別競走成績である。分析 に用いたデータは，このなかで1982年度から1987 年度までの 6 年間に得られた各馬の競走成績であ る。この内, 去勢馬と障害出走馬をあらかじめ除 外し，その後に 3 歳産子で30頭，4歳産子で50頭， 5 歳産子では 20 頭以上の競走成績を持つ種雄馬の 後代の記録を取り上げた。分析に用いられた各年 齢ごとの父馬数とその後代総数は Table 1 に示 す通りであった。

遺伝率は, 年間収得賞金額とそれを出走回数で 除した出走当り平均収得賞金額 (平均収得賞金額 とする）の 2 項目について推定した。さらにそれ らのらちで収得賞金額の分布を正規分布に近似さ せる手法として良く用いられる平方根，4乗根， および自然対数変換值についても遺伝率を推定し， 評価値の最適な尺度変換についても検討を加えた。

な拈各出走年齢別の年間収得金額とその变換值 の分布特性值および Kolomogorov による正規性 の検定は, 統計分析システム SAS の UNIVARI-
ATE プロシジャを用いて計算を行なった〔6]。 また遺伝率推定の統計モデルは，出走年度と性を 母数効果とし，父ウマと残差を変量効果とする次 式を仮定した。

$$
\begin{aligned}
& \mathrm{Y}_{\mathrm{ijkl} 1}=\mu+\mathrm{T}_{\mathrm{i}}+\mathrm{S}_{\mathrm{j}}+\mathrm{G}_{\mathrm{k}}+\mathrm{e}_{\mathrm{ijk} 1} \\
& \text { ここで } \\
& \mathrm{Y}_{\mathrm{ijk} 1}: \text { 後代の形質值 }
\end{aligned}
$$

$\mu:$ 全平均

$\mathrm{T}_{\mathrm{i}}$ ： $\mathrm{i}$ 番目の出走年度に共通な効果 $(\mathrm{i}=1$, $2, \sim, 6$ )

$\mathrm{S}_{\mathrm{j}}: \mathrm{j}$ 番目の性に共通な効果 $(\mathrm{j}=1,2)$

$\mathrm{G}_{\mathrm{k}}: \mathrm{k}$ 番目の父ウマに共通な効果 $(\mathrm{k}=1,2$,

$$
\sim, 72 ; 84 ; 82 \text { ) }
$$

$\mathrm{e}_{\mathrm{ijk1}}$ : 残差

計算には, 同じく SAS の VARCOMP プロシ ジャを用い, 父ウマ分散と残差分散成分の推定は, オプションにある 4 種手法の内から TYPE 1 法 と制限付き最尤 (REML) 法との二通りの手法に より行なって,両者の比較をすることも試みた[7]。 遺伝率の值は, 得られた分散成分の推定值を用い て半きょらだい相関法によって求め, その標準誤 差は Swiger らの方法で推定した[8]。

\section{結果}

出走年齢別に個々の遺伝率を推定するのに先立 ち,まず年間収得賞金額と平均収得賞金額の 2 項 目の分布特性をとらえるために，その平均值，標 準偏差，変動係数拈よび歪度，尖度を Table 2 と Table 3 に示した。Table 2 を見ると，年間 收得賞金額の平均值は出走時の年齢が進むにつれ て増加する傾向にあるが，いずれの標準偏差も極 めて大きく，変動係数はいずれも $150 \%$ を越える 值であった。また分布の特性を表わす歪度と尖度 の值は，用いた記録が正規分布であるならばこの 場合はそれぞれ0を示すが，得られた值はどれも これらの值からかけ離れたものであった。一方，

Table 1. Number of horses and sires by age-of-horse group in data used for estimation of heritabilities

\begin{tabular}{ccccc}
\hline \multirow{2}{*}{ Age of horse } & \multicolumn{3}{c}{ No. of horses } & No. of sires \\
\cline { 2 - 4 } & Total & Female & Male & 72 \\
\hline 3 years & 3,675 & 1,665 & 2,010 & 84 \\
4 years & 7,999 & 3,737 & 4,262 & 82 \\
5 years & 3,454 & 1,385 & 2,069 & \\
\hline
\end{tabular}

Data were restricted to include offspring of sires having at least thirty (3-yr), fifty (4-yr), twenty (5-yr) progeny. 
Table 2. Distributional properties of annual earnings (E) for horses in three age groups

\begin{tabular}{|c|c|c|c|c|c|}
\hline Age of horse and transformation & Mean & $\mathrm{SD}$ & $\mathrm{CV}(\%)$ & Skewness & Kurtosis \\
\hline \multicolumn{6}{|l|}{3 years } \\
\hline Earnings $(E)^{\mathrm{a}}$ & 376.1 & 593.0 & 157.7 & 4.3 & 28.5 \\
\hline Square root of $\mathrm{E}$ & 14.7 & 12.7 & 86.3 & 1.0 & 1.8 \\
\hline Fourth root of $\mathrm{E}$ & 3.2 & 2.1 & 66.4 & -0.4 & -0.9 \\
\hline Natural logarithm of $\mathrm{E}$ & 4.2 & 2.6 & 62.6 & -0.7 & -1.0 \\
\hline \multicolumn{6}{|l|}{4 years } \\
\hline Earnings $(\mathbf{E})^{\mathrm{a}}$ & 742.1 & 1376.3 & 185.5 & 9.0 & 150.0 \\
\hline Square root of $\mathbf{E}^{b}$ & 20.5 & 18.0 & 87.7 & 1.3 & 5.0 \\
\hline Fourth root of $\mathrm{E}$ & 3.8 & 2.5 & 65.6 & -0.3 & -0.8 \\
\hline Natural logarithm of $\mathrm{E}$ & 4.7 & 2.9 & 60.8 & -0.8 & -0.9 \\
\hline \multicolumn{6}{|l|}{5 years } \\
\hline Earnings $(\mathbf{E})^{\mathrm{a}}$ & 1035.8 & 1660.1 & 160.3 & 5.2 & 54.7 \\
\hline Square root of $\mathrm{E}$ & 24.1 & 21.3 & 88.2 & 1.0 & 1.8 \\
\hline Fourth root of $\mathrm{E}$ & 4.1 & 2.7 & 66.6 & -0.3 & -0.9 \\
\hline Natural logarithm of $E$ & 5.0 & 3.0 & 61.2 & -0.8 & -1.0 \\
\hline
\end{tabular}

a: Expressed in ten thousand yen.

$\mathrm{b}$ : The smallest value of the Kolomogorov $\mathrm{D}$ statistic is $0.127(\mathrm{P}<0.01)$ in this table.

Table 3. Distributional properties of annual earnings per start (EPS) for horses in three age groups

\begin{tabular}{|c|c|c|c|c|c|}
\hline Age of horse and transformation & Mean & $\mathrm{SD}$ & $\mathrm{CV}(\%)$ & Skewness & Kurtosis \\
\hline \multicolumn{6}{|l|}{3 years } \\
\hline Earnings per start (EPS)a & 108.5 & 156.0 & 143.8 & 3.5 & 19.7 \\
\hline Square root of EPS & 8.0 & 6.7 & 83.7 & 0.8 & 0.9 \\
\hline Fourth root of EPS & 2.4 & 1.6 & 65.7 & -0.4 & -1.0 \\
\hline Natural logarithm of EPS & 3.4 & 2.2 & 64.3 & -0.6 & -1.1 \\
\hline \multicolumn{6}{|l|}{4 years } \\
\hline Earnings per start (EPS $)^{\mathrm{a}}$ & 96.8 & 199.0 & 205.7 & 10.8 & 187.0 \\
\hline Square root of EPSb & 7.5 & 6.4 & 86.1 & 1.6 & 8.3 \\
\hline Fourth root of EPS & 2.3 & 1.5 & 64.2 & -0.4 & -0.6 \\
\hline Natural logarithm of EPS & 3.3 & 2.1 & 62.9 & -0.6 & -1.0 \\
\hline \multicolumn{6}{|l|}{5 years } \\
\hline Earnings per start $(\text { EPS })^{\mathrm{a}}$ & 141.5 & 266.7 & 188.5 & 8.1 & 116.0 \\
\hline Square root of EPS & 8.9 & 7.8 & 87.8 & 1.4 & 5.2 \\
\hline Fourth root of EPS & 2.5 & 1.6 & 65.4 & -0.3 & -0.7 \\
\hline Natural logarithm of EPS & 3.5 & 2.2 & 63.2 & -0.6 & -1.0 \\
\hline
\end{tabular}

a: Expressed in ten thousand yen.

$\mathrm{b}$ : The smallest value of the Kolomogorov $\mathrm{D}$ statistic is $0.123(\mathrm{P}<0.01)$ in this table.

年間収得賞金額を平方根，4乗根と自然対数に変 換した值は,どの年齢に扔いても,変動係数はかな り小さくなり，なかでも自然対数変換值は $60 \%$ 前 後の值を示し顕著に小さくなった。さらに歪度と 尖度においても，各変換值は Kolomogorov の正 規性の検定結果からは外れるものの，記録の分布 をある程度は正規分布に近づけることを窥わせた。

Table 3 に示した平均収得賞金額の特性は, 平 均值に沶いて，年齢ごとの差があまり大きくなく なった点を除き, 標準偏差, 変動係数, 丕度と尖 度は，年間収得賞金額の結果とほぼ同様の傾向を 示し，また 3 種の変換の影響も，両者の間で大き
な相違は見られなかった。

年間収得賞金額と各変換值について，出走年齢 ごとに求めた遺伝率とその標準誤差を分散成分の 2 つの推定方法別に Table 4 に示した。年齢ごと の遺伝率を比べると, いずれも 3 歳馬の值が最も 高く, ついで 4 歳馬の值はこれよりもわずかに低 下し,さらに 5 歳馬になるとその值は 0.08 以下と かなり低く推定された。分散成分の推定方法間で 比較すると, 3 歳馬と 4 歳馬で TYPE 1 法より も REML 法を用いた方が遺伝率はやや小さく推 定される傾向を示したが，その影響は比較的小さ かった。一方，収得賞金額を各種変換したときの 
Table 4. Estimates of heritability $\left(\mathrm{h}^{2}\right)$ and standard errors (SE) of annual earnings (E) for Thoroughbreds by age-of-horse group

\begin{tabular}{|c|c|c|c|c|c|c|}
\hline \multirow{3}{*}{ Method and transformation } & \multicolumn{6}{|c|}{ Age of horse } \\
\hline & \multicolumn{2}{|c|}{3 years } & \multicolumn{2}{|c|}{4 years } & \multicolumn{2}{|c|}{5 years } \\
\hline & $\mathrm{h}^{2}$ & $\mathrm{SE}$ & $\mathrm{h}^{2}$ & $\mathrm{SE}$ & $\mathrm{h}^{2}$ & $\mathrm{SE}$ \\
\hline \multicolumn{7}{|l|}{ TYPE 1a } \\
\hline Earnings (E) & 0.12 & 0.03 & 0.08 & 0.02 & 0.05 & 0.02 \\
\hline Square root of $\mathrm{E}$ & 0.18 & 0.04 & 0.14 & 0.03 & 0.08 & 0.03 \\
\hline Fourth root of $\mathrm{E}$ & 0.16 & 0.04 & 0.13 & 0.03 & 0.07 & 0.03 \\
\hline Natural logarithm of $\mathrm{E}$ & 0.14 & 0.03 & 0.11 & 0.02 & 0.06 & 0.02 \\
\hline \multicolumn{7}{|l|}{ REML $^{b}$} \\
\hline Earnings (E) & 0.11 & 0.03 & 0.08 & 0.02 & 0.06 & 0.02 \\
\hline Square root of $\mathrm{E}$ & 0.16 & 0.04 & 0.13 & 0.03 & 0.08 & 0.03 \\
\hline Fourth root of $\mathrm{E}$ & 0.15 & 0.04 & 0.12 & 0.02 & 0.07 & 0.03 \\
\hline Natural logarithm of $E$ & 0.13 & 0.03 & 0.10 & 0.02 & 0.06 & 0.02 \\
\hline
\end{tabular}

a: Variance components estimated by the TYPE 1 method.

b: Variance components estimated by the REML method.

Table 5. Estimates of heritability $\left(\mathrm{h}^{2}\right)$ and standard errors (SE) of annual earnings per start (EPS) for Thoroughbreds by age-of-horse group

\begin{tabular}{|c|c|c|c|c|c|c|}
\hline \multirow{3}{*}{ Method and transformation } & \multicolumn{6}{|c|}{ Age of horse } \\
\hline & \multicolumn{2}{|c|}{3 years } & \multicolumn{2}{|c|}{4 years } & \multicolumn{2}{|c|}{5 years } \\
\hline & $\mathrm{h}^{2}$ & $\mathrm{SE}$ & $\mathrm{h}^{2}$ & $\mathrm{SE}$ & $\mathrm{h}^{2}$ & $\mathrm{SE}$ \\
\hline \multicolumn{7}{|l|}{ TYPE $1 \mathrm{a}$} \\
\hline Earnings per start (EPS) & 0.22 & 0.05 & 0.08 & 0.02 & 0.04 & 0.02 \\
\hline Square root of EPS & 0.25 & 0.05 & 0.15 & 0.03 & 0.08 & 0.03 \\
\hline Fourth root of EPS & 0.20 & 0.04 & 0.13 & 0.03 & 0.07 & 0.03 \\
\hline Natural logarithm of EPS & 0.19 & 0.04 & 0.12 & 0.03 & 0.07 & 0.03 \\
\hline \multicolumn{7}{|l|}{ REMLb } \\
\hline Earnings per start (EPS) & 0.19 & 0.04 & 0.07 & 0.02 & 0.05 & 0.02 \\
\hline Square root of EPS & 0.23 & 0.05 & 0.13 & 0.03 & 0.08 & 0.03 \\
\hline Fourth root of EPS & 0.18 & 0.04 & 0.12 & 0.02 & 0.07 & 0.03 \\
\hline Natural logarithm of EPS & 0.17 & 0.04 & 0.12 & 0.02 & 0.07 & 0.03 \\
\hline
\end{tabular}

a: Variance components estimated by the TYPE 1 method.

b: Variance components estimated by the REML method.

遺伝率は，いずれの年齢に抢いても，無変換の值 よりも大きく, 平方根変換は最も高い值を示し, 次に 4 乗根変換, そして自然対数変換の順であっ た。また, 得られた遺伝率の標準誤差は全般に 0.02〜0.04の範囲で小さかった。

Table 5 には平均収得賞金額に怙ける各遺伝率 とその標準誤差を示した。年齢ごとの遺伝率を比 ベると, ここでも 3 歳馬の值が最も高く, ついで 4 歳馬， 5 歳馬の順であった。しかし，4 歳馬と 5 歳馬の值は先の Table 4 とほぼ同程度の範囲な のに対して，3 歳馬の遺伝率は出走回数を考慮す ることで 0.20 前後のさらに高い值が得られた。分 散成分の推定方法の相違による影響は Table 4 と 同じ傾向にあったが, 各変換值の遺伝率はやや異
なり，4歳馬と 5 歳馬では変換に伴っていずれも 無変換よりも高い值が得られたのに対し，3歳馬 では平方根变換を除きこのような傾向は得られな かった。しかし, 平方根変換值の遺伝率はいずれ の年齢でも一番高く推定されたことは Table 4 と 同様であり, 特に 3 歳馬の值は TYPE 1 法で 0.25 , REML 法で 0.23 となって, 本研究で推定 された遺伝率の内では最も高かった。

\section{考察}

競走馬の能力評価値として年間収得賞金額を用 いる時, この值の分布は, 0 ないし低額值の個体 が多数存在する一方でそれよりも高額值の個体は 徐々に少なくなって行くことから，その分布は指 
数曲線状になる。このため収得賞金額の遺伝率を 推定した報告の多くは対数変換を行なっている $[3$, 9]。今回の分析に扣いても, 収得賞金額の対数変 換は, 変動係数を小さくし，さらに分布を正規分 布に近づけることが窥われた。しかし，推定され た遺伝率全般を見ると, 平方根変換值の遺伝率の 方が対数変換值よりも高い值が示されており，こ の結果は, Ojala の報告と一致するものであった [5]。本来競走馬の持つ真の競走能力は正規分布 を仮定できると思われるが，実際に利用できる年 間収得賞金額の記録は，収得賞金額のない個体が 3 歳馬の例で全体の約 $26 \%$ と多数存在するので, こうした変換を行なっても, 全体の分布を十分正 規分布に改善したとは言えない。今後もこの点の 適切な対処方法を検討することは必要と考兄られ る。

出走年齢別の遺伝率推定值は, 3 歳馬で最も高 く, 次に 4 歳馬, 5 歳馬では 0.08 以下と極めて低 くなった。Langlois と Tolley らの総説を見ると ポーランドの Fedorski はやはり 5 歳馬では同程

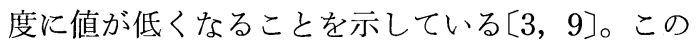
ことは, 5 歳馬になると 3 歳, 4 歳の競走成績か ら比較的競走能力の優れたウマに限って出走して いることが推定值に影響したものと推察される。 また， 3 歳馬の遺伝率が高いのは, 同年齢のウマ がほぼ同じ条件で短距離の競走を行なっている点 の特徵が挙げられる。3 歳馬については渡辺らも 既に0.49の高い遺伝率を報告しているが，それに 比べて本研究の值は低いが，この相違の原因は明 らかでない[10]。

年間収得賞金額と平均収得賞金額の遺伝率を比 ベると，3歳馬では Langlois と Ojara の報告と 同様に，平均収得賞金額の遺伝率の方がより高く 推定された $[3,5]$ 。一方， 4 歳と 5 歳馬について は, ほとんどその差が認められなかった。平均出 走回数は, 3 歳馬では 3.4 回であるのに対し，4

歳, 5 歳馬では 7 回とより多くなっている。

分散成分の推定方法は，これまで広く用いられ てきた Henderson の 3 法と同等の TYPE 1 法と, Patterson らによって提案され, 近年ウマ能力の 遺伝的パラメータの推定に用いられているREML 法の両法を行なってそれらの比較を試みた $[1,2$, 7】。しかし, 本研究の分析結果に拈いては, 両法
の遺伝率推定值の間で特に顕著な差異はなかった。 年間収得賞金額の遺伝率を推定する際に, 本研 究では父ウマのほかに出走年度と性の 2 つの要因 だけを考慮に入れて分析を行なった。この点に関 して Ojara らは, フィンランドの競走馬の年間最 高タイムに関与する諸要因を検討し，その中で出 走年度, 季節と性の 3 つを要因としたモデルが最 も高い遺伝率であることを報告している〔4】。し かし, 本研究において利用された競馬年鑑の記録 では限られた情報しか得られなかったことから， 今回の分析は先の 2 要因だけを取り上げた。これ に対して，山本らは既にサラブレッド種の走行タ イムに関与する諸要因の影響を検討している〔11， 12]。今後サラブレッド種の年間収得賞金額に関 与する諸要因について同様な分析をすることは, 興味ある問題と思われた。

\section{要 約}

サラブレッド種の中央競馬における各馬の年間 収得賞金額記録が種雄馬別に記載されている競馬 年鑑を用い，この年間収得賞金額の遺伝率につい て，SAS を使って推定した。供試記録は，1982 年度から1987年度の 6 年間に 3 歳馬で 30 頭, 4 歳 馬で50頭，5歳馬では20頭以上の後代記録を持つ 種雄馬それぞれ $72,84,82$ 頭とその後代 総数 $3,675 ， 7,999 ， 3,454$ 頭を取り上げた。分析モデ ルは，出走年度と性を母数効果とし，父ウマと残 差を変量効果と仮定し, 遺伝率は半きょらだい相 関法により求めた。

年間収得賞金額の分布は正規分布からかけ離れ ているので，平方根，4乗根と自然対数の 3 種変 換を試みたところ, 平方根変換值の遺伝率が最も 高い傾向にあった。出走年齢別の遺伝率を見ると， 3 歳馬が一番高く, 次いで 4 歳馬, 5 歳馬では 0.08 以下の低い值であった。出走回数を考慮した 出走当たり平均収得賞金額の遺伝率は, 3 歳馬に おいて年間収得賞金額の值よりも高くなり，この 時の平方根変換值の遺伝率は，分散成分を SAS の TYPE 1 法で求めると 0.25 , 制限付き最尤法 で0.23となり，今回推定した各遺伝率のなかでは 最も高い值を示した。 


\section{謝辟}

本研究の取りまとめにあたり，終始有益なご助言をい ただいた北海道大学農学部の清水 弘教授に深謝いたし ます。

\section{引用 文 献}

1. Huizinga, H. A. and Van der Meij, G. J. W. (1989). Estimated parameters of performance in jumping and dressage competition of the Dutch Warmblood horse. Livest. Prod. Sci. 21: 333-345.

2. Huizinga, H. A., Boukamp, M., and Smolders, G. (1990). Estimated parameters of field performance testing of mares from the Dutch Warmblood riding horse population. Livest. Prod. Sci. 26: 291-299.

3. Langlois, B. (1980). Heritability of racing ability in thoroughbreds-a review. Livest. Prod. Sci. 7: 591-605.

4. Ojala, M., Van Vleck, L. D., and Quaas, R. L. (1987). Factors influencing best annual racing time in Finnish horses. J. Anim. Sci. 64: 109-116.

5. Ojala, M. (1987). Heritabilities of annually summarized race records in trotters. J. Anim. Sci. 64: $117-125$.
6. SAS Institute Inc. (1986). SAS Procedures Guide for Personal Computers (日本語版). Version 6 Edition, pp. 394-409. SAS Institute Inc., Cary, NC.

7. SAS Institute Inc. (1988). SAS/STAT User's Guide. Release 6.03 Edition, pp. 967-978. SAS Institute Inc., Cary, NC.

8. Swiger, L. A., Harvey, W. R., Everson, D. O., and Gregory, K. E. (1964). The variance of intraclass correlation involving groups with one observation. Biometrics 20: 818-826.

9. Tolley, E. A., Notter, D. R., and Marlowe, T. J. (1985). A review of the inheritance of racing performance in horses. Anim. Breed. Abstr. 53: 163-185.

10. Watanabe, Y., Shimoiizaka, T., and Sato, K. (1965). An analysis of the racing performances of thoroughbreds in Japan. Res. Bull. Livestock Farm, Fac. Agr. Hokkaido Univ. 1: 1-7.

11. 山本 修, 佐々木義之, 沖 博憲 (1989). サラブ レッド種の走行タイムに関与する要因. 第 81 回日本 畜産学会大会講演要旨 : 140.

12. 山本 修, 佐々木義之, 沖 博憲 (1989). サラブ レッド種の走行タイムに対する競走条件・開催月・ 年齢の影響. 第 81 回日本畜産学会大会講 演要旨: 141 . 